\title{
Incorporation of intermediary products of 5-FU anabolism into colorectal cancer
}

\author{
G R GILES, LINDA WOODHOUSE, P J FINAN, AND E M CHISHOLM \\ From the University Department of Surgery, St James's University Hospital, Leeds
}

SUMMARY In 18 patients intermediary anabolic metabolites of 5-FU were measured in normal colonic mucosa and colorectal cancer tissue of intravenous bolus injection or continuous infusion. Higher total concentrations of 5-FU products were found in the cancers when compared with normal colonic tissue. There appeared to be no evidence, however, that some patients had a selectively increased ability to incorporate 5-FU into their tumours. Overall higher concentrations of tumour incorporation of 5-FU were found after bolus injection rather than the infusion method, although this difference is statistically not significant.

5-Fluorouracil (5-FU) appears to be the most active cytotoxic agent against colorectal cancer. Using clinical criteria of objective responses it would seem that about $10-26 \%$ of patients with advanced cancer have tumour masses which reduce in size after optimal treatment. ${ }^{1}$ As the cytotoxic action requires incorporation of the agent into tumour cells, a failure to show a response may imply that in these patients there had been a failure of incorporation of 5-FU into the tumour and its conversion to active metabolites because of some intrinsic intracellular defect, or that insufficient 5-FU was activated because of a failure of drug delivery to the tumour tissue, or both explanations may apply.

The activation of 5-FU is a complex process with two main pathways leading to either reduction of DNA synthesis via inhibition of the enzyme thymidylate synthetase ${ }^{23}$ or by direct incorporation into RNA $^{4} 5$ (Fig. 1). The biochemical injury produced by this drug requires more detailed research but it is also possible to investigate the relative inefficiency of 5-FU by investigating the metabolism of 5-FU into its intermediate metabolites which are essential requirements in order that permanent damage of cancer cells can occur.

In this study we have investigated 5-FU incorporation into human colorectal cancer tissue and have measured the concentrations of fluorouracil (FU), fluorouridine (FUR) and fluorodeoxyuridine (FdUR) in the cancer and excised normal colonic mucosa. Two methods of 5-FU administration,

Address for correspondence: Professor G R Giles, Department of Surgery, St James's University Hospital, Leeds LS9 7TF.

Received for publication 28 May 1985 bolus injection and continuous intravenous infusion, are compared in terms of the levels of metabolites achieved. In addition two enzymes concerned in the incorporation of 5-FU into the RNA pathway were also assayed.

\section{Methods}

PATIENTS

Eighteen patients with colorectal cancer gave informed consent to receiving a single preoperative dose of 5-FU before excision of their cancer. The study had been approved by the local hospital ethical committee.

Of the 18 patients who were investigated 14 were

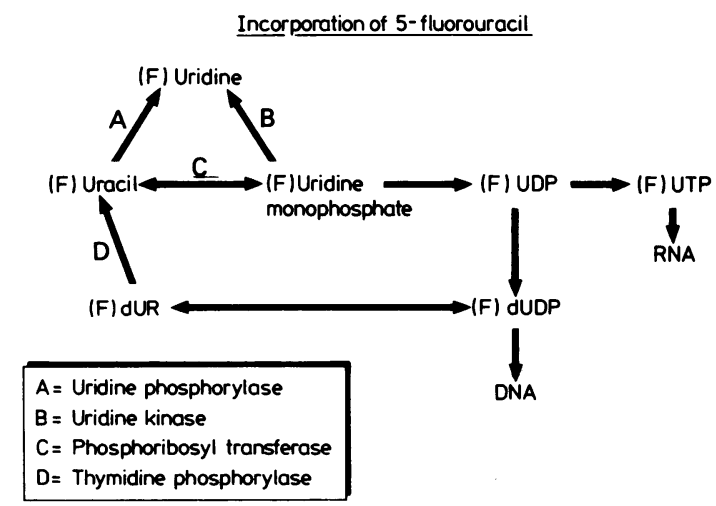

Fig. 1 Illustrates schematically the anabolic pathways of 5-FU into DNA and RNA metabolism. 
men and four women. The mean age of the group was $68 \cdot 2 \pm 9 \cdot 1$ years. Six patients had rectal cancer, eight had left sided colonic cancer and the remainder had right sided colonic cancer. Patients were prepared for colonic surgery by bowel preparation and blood transfusion where necessary 48 hours before operation. They were randomised to receive 5-FU at a dose of $15 \mathrm{mg} / \mathrm{kg}$ either by continuous infusion over 24 hours or by rapid intravenous bolus injection over five minutes.

At the time of surgery samples of both normal and malignant colonic epithelium were taken from the freshly excised specimens, snap frozen in liquid nitrogen and stored at $-70^{\circ} \mathrm{C}$. Tissue extracts were obtained by homogenising the specimens in an equal volume of ice cold $10 \mathrm{mmol}$ tris/ $\mathrm{HCl}$ buffer $(\mathrm{pH} \mathrm{7.5)}$, containing $10 \mathrm{mmol}$ mercaptoethanol, centrifuging at $100000 \mathrm{~g}$ for 30 minutes at $4^{\circ} \mathrm{C}$ and collecting the supernatant to store at $-70^{\circ} \mathrm{C}$. All reagents except where otherwise stated were of analytical grade, from BDH Chemicals Ltd (Poole).

\section{ENZYME STUDIES}

The assay of phosphoribosyl transferase (PRT) (EC 2.4.2.9) was adapted from the radio-isotopic method described by Reyes. ${ }^{6}$ Sixty microlitres of extract $(10$ $\mathrm{mmol}$ tris $/ \mathrm{HCl} \mathrm{pH} \mathrm{7.5)} \mathrm{was} \mathrm{incubated} \mathrm{at} 37^{\circ} \mathrm{C}$ for 30 minutes with $20 \mu \mathrm{l}$ of $6.0 \mathrm{mmol}\left[6-{ }^{3} \mathrm{H}\right] 5-\mathrm{FU}$ (Amersham), $20 \mu \mathrm{l}$ of $400 \mathrm{mmol}$ tris $(\mathrm{HCl})(\mathrm{pH} \mathrm{9.8)}$ and $40 \mu \mathrm{l}$ of $15.0 \mathrm{mmol} 5$-phosphoribosyl-1pyrophosphate in $15 \mathrm{mmol} \mathrm{MgCl}_{2}$. Twenty microlitre aliquots were taken at $0,10,20$, and 30 minutes and mixed with $500 \mu 1750 \mathrm{mmol}$ ammonium acetate (pH 9.0). The amount of $\left[6-{ }^{3} \mathrm{H}\right]$ FUMP formed was measured by applying the mixture to a boronate affinity gel prepared as described by Uziel et al. ${ }^{7}$ The gel was eluted with $250 \mathrm{mmol}$ ammonium acetate (pH 8.8) to remove unconverted $\left[6-{ }^{3} \mathrm{H}\right]$ 5-FU and then with $100 \mathrm{mmol}$ formic acid to remove the $\left[6-{ }^{3} \mathrm{H}\right]$ FUMP. The latter was counted using a Phillips PW 4540 liquid scintillation analyser and the specific activity of the PRT expressed as nmol $\left[6-{ }^{3} \mathrm{H}\right]$ 5 FUMP produced/h/gram of protein. The protein content of the supernatant was determined using the Biuret method.

The assay of uridine kinase (UK) - (EC 2.7.1.48) was based on the radio-isotopic method described by Ahmed et al. ${ }^{8}$ Forty microlites of extract in 10 mmol tris $\mathrm{HCl}, \mathrm{pH} 7.5(600-900 \mu \mathrm{g}$ protein) was incubated for 40 minutes at $37^{\circ} \mathrm{C} \mathrm{plC}$ with $40 \mu \mathrm{l}$ of 50 mmol $\left[5,6-{ }^{3} \mathrm{H}\right]$ uridine (Amersham), $40 \mu \mathrm{l}$ of $69 \cdot 5$ mmol AATP, $40 \mu \mathrm{l}$ of $62.4 \mathrm{mmol} \mathrm{MgCl}_{2}$ and $40 \mu \mathrm{l}$ of $\mathrm{mol}$ tris $/ \mathrm{HCl}(\mathrm{pH} 7.5)$ containing $50 \mathrm{mmol} \mathrm{B-}$ mercaptoethanol. Twenty microlitre aliquots were taken at 2,10,20,30, and 40 minutes and spotted on DE-81 discs (Whatman Biochemical Ltd). Uncon- verted $\left[5,6-{ }^{3} \mathrm{H}\right]$ uridine was eluted from the discs with a continuous stream of water. $\left[5,6-{ }^{3} \mathrm{H}\right]$ uridine monophosphate (UMP) was eluted from the disc in $1 \mathrm{ml}$ of $0.1 \mathrm{~mol} \mathrm{HCl} 0.5 \mathrm{~mol} \mathrm{NaCl}$ into scintillation vials and counted in a liquid scintillation analyser (Phillips PW 4540). The specific activity of UK was expressed as nmols of $\left[5 \cdot 6-{ }^{3} \mathrm{H}\right] \mathrm{UMP} / \mathrm{h} / \mathrm{g}$ of protein in extract.

\section{FLUORINATED COMPOUNDS}

One hundred milligrams of frozen tissue was homogenised in $2 \mathrm{ml}$ of ice cold $2 \mathrm{~mol} \mathrm{Na} \mathrm{F}$ and 200 $\mu \mathrm{l}$ of ice cold $10 \mathrm{~mol}$ acetic acid was immediately added to precipitate the proteins. The acidic homogenate was frozen and thawed three times and then centrifuged at $500 \mathrm{~g}$ at $4^{\circ} \mathrm{C}$ for 20 minutes. The clear supernatant was retained and the pellet washed twice with $1 \mathrm{ml}$ of $10 \mathrm{~mol}$ acetic acid, with 20 minutes of mixing at $4^{\circ} \mathrm{C}$ between washes. The three supernatants were pooled, freeze-dried and stored at $-20^{\circ} \mathrm{C}$ until required.

The chromatographic analysis was done using an LDC modular system consisting of a chromatography control module (CCM), two Constametric III pumps, a variable wavelength UV detector, a Magnus Autosampler with Rheodyne valve and 50 $\mu l$ loop and a Houston Ominigraphic Printer Plotter.

The $250 \mathrm{~mm} \times 4.5 \mathrm{~mm}$ ID Spherisorb ODS $5 \mu \mathrm{m}$ column was protected by a dry packed $50 \mathrm{~mm} \times 4.5$ $\mathrm{mm}$ precolumn containing Whatman CO:PELL ODS.

A gradient elution using a low concentration buffer $0.02 \mathrm{~mol} \mathrm{KH}_{2} \mathrm{PO}_{4}$ (pH 5.6) and high concentration buffer $60 / 40 \mathrm{vol} / \mathrm{vol}$ methanol/water. The gradient was introduced at $0.69 \% / \mathrm{min}$ of high concentration buffer, at a flow rate of $1 \mathrm{ml} / \mathrm{min}$ and a run time of 35 minutes. The compounds were quantified at a wavelength of $254 \mathrm{~nm}$ and an AUFS of 0.01 .

The retention times for FU, FUR and FdUR were $7.56 \pm 0.06 \mathrm{~min}, 13.49 \pm 0.11 \mathrm{~min}$ and $16.62 \pm 0.11$ min with standards run after every eighth sample. The results are expressed as $\mathrm{ng} / \mathrm{ml}$ of supernatant. All statistical analyses were conducted as Mann Whitney U tests.

\section{Results}

Table 1 summarises the group data concerning concentrations of fluorouracil, fluorouridine, and fluorodeoxyuridine in normal colonic mucosa and colorectal cancer tissue. The mean concentrations of FU detected in the cancer tissue were 20.4 $\pm 13 \cdot 1$ and $9.5 \pm 5.5 \mathrm{ng} / \mathrm{ml}$ after bolus and infusion respectively $(p<0.05)$. After bolus injection this was significantly 
Table 1 Mean concentrations of intermediary metabolites

\begin{tabular}{|c|c|c|c|c|c|}
\hline & & $T F P$ & $F U$ & $F U R$ & FdUR \\
\hline Bolus & $\begin{array}{l}\text { Normal mucosa } \\
\text { Tumour }\end{array}$ & $\begin{array}{c}193 \pm 9.5 \\
38.7 \pm 20.6 \\
p<0.025\end{array}$ & $\begin{array}{l}8 \cdot 3 \pm 6 \cdot 4 \\
20 \cdot 4 \pm 13 \cdot 1 \\
p=0.025\end{array}$ & $\begin{array}{l}9 \cdot 3 \pm 8 \cdot 7 \\
17 \cdot 0 \pm 11 \cdot 2 \\
p<0.05\end{array}$ & $\begin{array}{l}1 \cdot 7 \pm 1 \cdot 0 \\
1 \cdot 2 \pm 1 \cdot 0 \\
\text { ns }\end{array}$ \\
\hline Infusion & $\begin{array}{l}\text { Normal mucosa } \\
\text { Tumour }\end{array}$ & $\begin{array}{c}11 \cdot 9 \pm 6 \cdot 23 \\
23 \cdot 6 \pm 9 \cdot 5 \\
p<0.01\end{array}$ & $\begin{array}{l}5 \cdot 3 \pm 2 \cdot 7 \\
9 \cdot 5 \pm 5 \cdot 5 \\
\text { ns }\end{array}$ & $\begin{aligned} 3 \cdot 9 \pm 4 \cdot 1 \\
12 \cdot 2 \pm 9 \cdot 0 \\
p=0 \cdot 02\end{aligned}$ & $\begin{array}{l}2 \cdot 8 \pm 1 \cdot 7 \\
1 \cdot 9 \pm 1 \cdot 7 \\
\text { ns }\end{array}$ \\
\hline
\end{tabular}

Mann-Whitney U test.

TFP=total fluorinated pyrimidines; $F U=$ fluorouracil; $F U R=$ fluorouridine; FdUR=fluorodeoxyuridine.

higher than normal colonic mucosa $(\mathrm{p}<0 \cdot 05>0 \cdot 01)$. Similarly the FUR concentrations in tumour tissue were $17 \cdot 0 \pm 11.2$ and $12.2 \pm 9.0 \mathrm{ng} / \mathrm{ml}$ after bolus and infusion. Again these concentrations were higher than normal colonic mucosa $(p<0.05>0.01)$. The concentrations of FdUR after both bolus and infusion, however, were similar in both normal mucosa and tumour tissue.

In Figures $2-4$ the individual values of these metabolites are shown in normal colonic mucosa and in neoplastic tissues. There appear to be two specimens of normal mucosa in which concentrations of FU are distinctly higher than other values,

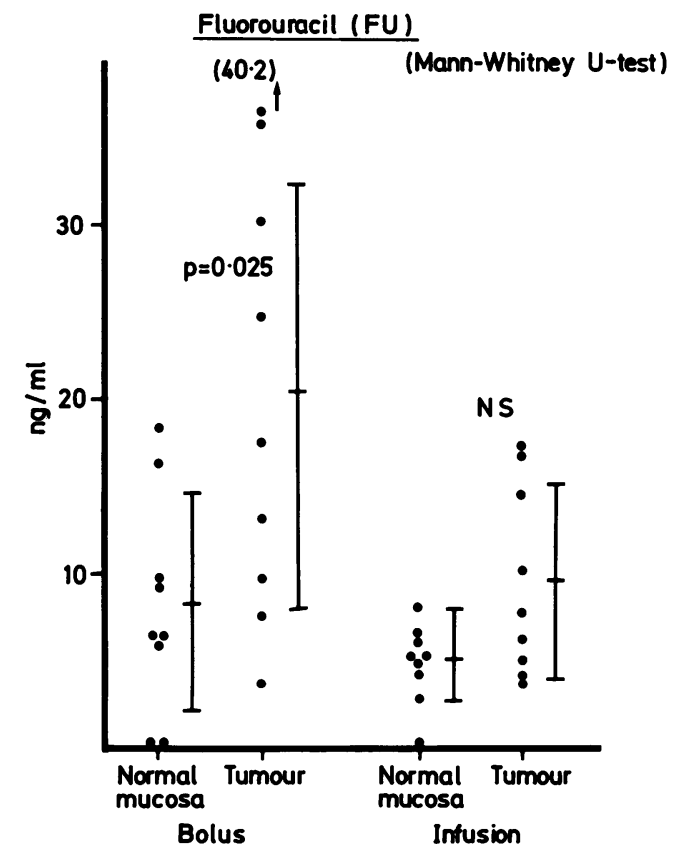

Fig. 2 Individual values of fluorouracil in normal and neoplastic colonic mucosa after bolus injection and continuous infusion of 5-FU. five have higher concentrations of FUR and four have distinctly higher concentrations of FdUR. Four specimens of neoplastic tissue have higher concentrations of FU, four exceptionally high concentrations of FUR and one high value of FdUR. These values appear to have occurred randomly, however, and no specimen showed consistently high concentrations of all three compounds. Thus there did not appear to be a subset of patients who were able to activate 5-FU more successfully than others and we cannot account for individual tumour suspectibility to 5-FU by these studies.

In Table 2 the data have been arranged differently

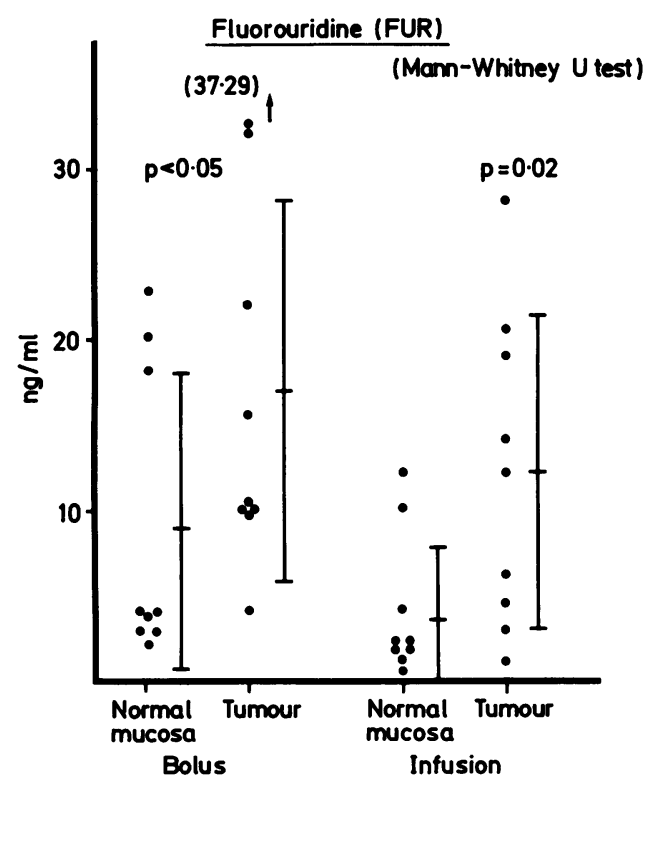

Fig. 3 Individual values of fluorouridine in normal and neoplastic colonic mucosa after bolus injection and continuous infusion of 5-FU. 


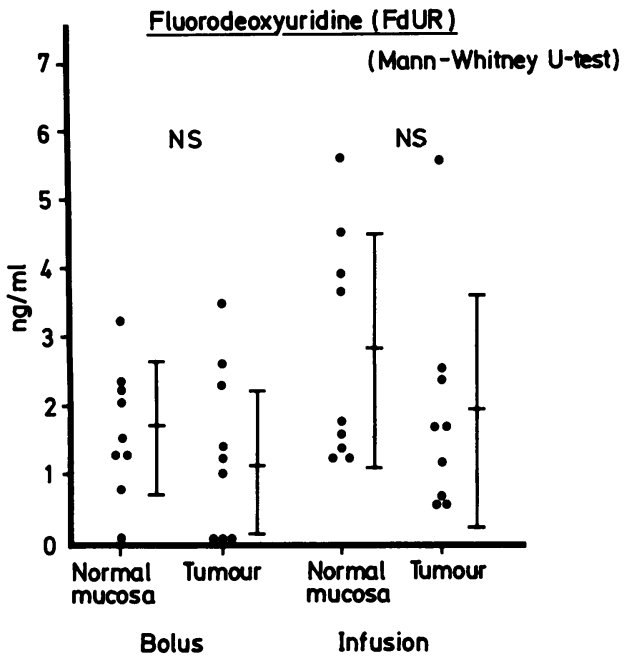

Fig. 4 Individual values of fluorodeoxyuridine in normal and neoplastic colonic mucosa after bolus injection and continuous infusion of $5-F U$.

so that comparisons between the concentrations achieved by bolus injection or continuous infusion are more easily seen. Significantly higher concentrations of FUR after bolus injection was found in normal mucosa, compared with continuous infusion. Similarly the concentrations of FU in tumour tissues were higher after bolus injection and just reached statistical significance at the $5 \%$ level. The concentrations of FdUR were not significantly different after either method of treatment.

\section{ACTIVATING ENZYME CONCENTRATIONS}

The concentrations of activating enzymes were similar in the groups of patients receiving either infusion or bolus of 5-FU and are not considered separately. The mean concentration of phosphoribosyl transferase in normal colonic mucosa was $11 \cdot 14 \pm 5.03 \mathrm{nmol} / \mathrm{h} / \mathrm{g}$ and $20.7 \pm 8.64$ in tumour tissue. The difference between the two tissues was significantly different $(\mathrm{p}<0 \cdot 01)$.

The mean uridine kinase concentration in normal colonic mucosa was $2.04 \pm 1.31 \mathrm{nmol} / \mathrm{h} / \mathrm{g}$ compared with $3.73 \pm 2.0$ in tumour tissue $(p>0.05)$. There was no significant correlation of the total fluorinated pyrimidines in tumour tissue and the concentrations of uridine kinase $(r=0.44)$ or the concentrations of phosphoribosyl transferase $(r=0 \cdot 12)$ nor between enzyme levels and intermediate metabolites. Similarly the total fluorinated compounds or other fractions in normal colonic mucosa could not be correlated to uridine kinase $(r=0 \cdot 11)$ or phosphoribosyl transferase levels $(r=0 \cdot 13)$.

\section{Discussion}

In order to produce cell damage, 5-FU must be converted within the cell to either fluorodeoxyuridine monophosphate (FdUMP), which acts to inhibit thymidilate synthetase and DNA synthesis, ${ }^{23}$ or fluorouridine triphosphate (FTUP), which is incorporated into, and interferes with, the function of RNA. ${ }^{45}$ The formation of both these nucleotides is preceded by the conversion of 5-FU to fluorouridine monophosphate (FUMP), which can occur by two pathways: the sequential action of the enzymes uridine phosphorylase and uridine kinase, or by a direct conversion to FUMP by the action of phosphoryibosyl transferase (Fig. 1). An alternative route may involve the action of thymidine phosphorylase and thymidine kinase with the formation of an intermediate metabolite of fluorodeoxyuridine (FdUR). The formation of FdUMP and FUTP may be reflected in the levels of 5-FU, FdUR and FUR, which can be found in the tissue under investigation. The association of these compounds with the pharmokinetics of 5-FU, as detected in plasma concentrations, remains to be established.

The relatively poor clinical response to 5-FU therapy and the similarity of clinical response rate over a fairly wide range of dose regimens argue in favour of the idea that there may be some selectivity in the metabolic incorporation of 5-FU, which is due

Table 2 Comparisons of intermediary products after infusion or bolus injection

\begin{tabular}{|c|c|c|c|c|c|}
\hline & & $T F P$ & $F U$ & $F U R$ & $F d U R$ \\
\hline Normal mucosa & $\begin{array}{l}\text { Infusion } \\
\text { Bolus }\end{array}$ & $\begin{array}{l}11 \cdot 9 \pm 6 \cdot 23 \\
19 \cdot 3 \pm 9 \cdot 5 \\
p=0.05\end{array}$ & $\begin{array}{l}5 \cdot 3 \pm 2 \cdot 7 \\
8 \cdot 3 \pm 6 \cdot 4 \\
\text { ns }\end{array}$ & $\begin{aligned} 3.9 \pm 4 \cdot 1 \\
9 \cdot 3 \pm 8 \cdot 7 \\
p<0.05\end{aligned}$ & $\begin{array}{l}2 \cdot 8 \pm 1 \cdot 7 \\
1 \cdot 7 \pm 1 \cdot 0 \\
\text { ns }\end{array}$ \\
\hline Tumour & $\begin{array}{l}\text { Infusion } \\
\text { Bolus }\end{array}$ & $\begin{array}{l}23 \cdot 6 \pm 9 \cdot 5 \\
38 \cdot 7 \pm 20 \cdot 6 \\
\text { ns }\end{array}$ & $\begin{array}{l}9.5 \pm 5 \cdot 5 \\
20 \cdot 4 \pm 13 \cdot 1 \\
p<0.05\end{array}$ & $\begin{array}{l}12 \cdot 2 \pm 9 \cdot 0 \\
17 \cdot 0 \pm 11 \cdot 2 \\
\text { ns }\end{array}$ & $\begin{array}{l}1 \cdot 9 \pm 1 \cdot 7 \\
1 \cdot 2 \pm 1 \cdot 0 \\
\text { ns }\end{array}$ \\
\hline
\end{tabular}

Mann-Whitney U test.

TFP=total fluorinated pyrimidines; $F U=$ fluorouracil; FUR=fluorouridine; FdUR=fluorodeoxyuridine. 
to either pharmokinetic differences or to the individual's ability to incorporate 5-FU at a cellular level. Our group has previously shown that the concentrations of uridine and thymidine phosphorylase in colorectal tumours are higher than those found in normal colonic mucosa ${ }^{9}$ so that the initial conversion of 5-FU to 5-fluorouridine or 5fluorodeoxyuridine should not be inhibited by enzyme lack. Similarly this study has shown that the concentrations of uridine kinase which act on the conversion of fluorouridine to fluorouridine monophosphate (FUMP) and phosphoribosyl transferase, which converts uracil directly to FUMP, are significantly raised in colonic cancer above the normal levels. ${ }^{10}$ These raised levels are probably an indication of increased cell turnover in the tumour tissue and suggest that the early enzymatic conversion of intracellular 5-FU should present no problem, as almost all tumours show a raised enzyme concentration. This factor does not appear to have discriminatory value to detect tumours unable to incorporate 5-FU which is contrary to previous reports. ${ }^{11}$ An analysis of specific activities of these enzymes, however, may ultimately identify responding patients as shown by Ardalan $e^{2}$ al $^{12}$ in a study of diphosphate kinases in breast cancer patients.

It has been shown ${ }^{13}$ that the ability of cell free supernatants of murine tumours to produce phosphorylated products of 5-FU can be correlated with in vitro sensitivity of the tumours to 5-FU. Furthermore tumours resistant to 5-FU in vivo showed distinctly different patterns of 5-FU phosphorylase in vitro, particularly in terms of concentration differences of diphosphate and triphosphate peaks. The same group of investigators ${ }^{12}$ have also shown that in patients with advanced breast cancer there are significant differences in the in vitro conversion of 5-FU to FUR and FdUMP in responding patients when compared with non-responding patients. This study has shown that 5-FU incorporation into human colorectal tumours can be detected as 5-fluorouracil, 5-fluorouridine or 5-deoxyfluorouridine. Colorectal cancer tissue appears to contain significantly more fluorinated products than normal colonic mucosa whether the drug is given by bolus or infusion regimen. This difference is, however, not expressed by changes in the measured concentrations of FdUR. It is also apparent that tumours from some patients apparently incorporate more 5-FU than others and this may ultimately identify those patients in whom it might be expected that a 5-FU cytotoxic effect could beneficially occur, though this is speculative at this time and requires formal clinical trial.

If as expected tumour sensitivity to 5-FU can be related to incorporation into RNA and DNA metabolism, then in vitro culture of explants with labelled 5-FU may also give some indication of drug effect. This method of sensitivity testing, however, does not take account of the pharmacokinetics of the agent, which may be relevant to the clinical response. ${ }^{14} 15$ In this study it has proved possible to compare the tumour incorporation of 5-FU after bolus or continuous infusion. The total fluorinated products, fluorouracil, and fluorouridine were higher in both normal colonic mucosa and tumour tissue after bolus injection than after a continuous 24 hour infusion. This did not apply to FdUR concentrations, however, which were equivalent. This is a surprising result as it might be expected that as RNA synthesis continues throughout the cell cycle - that is, not confined to the time of DNA replication that continuous infusion of 5-FU would give high concentrations of RNA incorporation - that is, raised concentrations of FUR. It is difficult to be certain that the temporal relationship of the drug delivery was strictly comparable between the two regimens but the results are nevertheless interesting. It illustrates the need to take account of drug handling by the patient, however, as lower concentrations of 5-FU in bone marrow have been shown after continuous infusion when compared with other methods of administration. ${ }^{16}$

If this approach of in vivo drug testing proves to correlate with clinical effect, it should also be possible to monitor the modulation of 5-FU incorporation - for example, as in sequential methotrexate-5-FU regimens or after priming of the tumour with thymidine and to optimise cytotoxic action. A comparison of tumour tissue and normal mucosa removed in the same operation may well predict drug toxicity and permit the development of new methods to protect the normal tissues.

\section{References}

1 Ansfield FJ, Curneri AR. Further clinical studies with 5-Fluorouracil. J Natl Cancer Inst 1959; 22: 497-501.

2 Heidelberger C. Fluorinated pyrimidines. Progr Nucl Acid Res Mot Biol 1965; 4: 1-50.

3 Langenbach RJ, Danenberg PV, Heidelberger C. Thymidylate synthetase: mechanism of inhibition by 5-fluoro-2'-deoxyuridylate. Biochem Biophys Res Commun 1972; 48: 1565-71.

4 Carrico CR, Glazer RI. Effect of 5-Fluorouracil on the synthesis and translation of polyadenylic acid containing RNA from regenerating liver. Cancer 1979; 39: 3694-701.

5 Mandel HR. Incorporation of 5-Fluorouracil into RNA and its molecular consequences. Prog Mol Subcell Biol 1969; 1: 82-135. 
6 Reyes P, Hall TC. Synthesis of 5-Fluorouridine-5'phosphate by pyrimidine phosphoribosyltransferase of mammalian origin. 1. Some properties of the enzyme from P1534J mouse leukaemic cells. Biochemistry 1969; 8: 2057-9.

7 Uziel M, Smith LH, Taylor SA. Modified nucleosides in wine: selective removal and analysis. Clin Chem 1976; 22: 1451-7.

8 Ahmed WK, Haggitt RC, Welch AD. Preliminary studies of the uridine kinase activity of human colorectal adenocarcinomas. Cancer 1981; 48: 1200-4.

9 Higley B, Oakes J, de Mello J, Giles GR. Pyrimidine nucleoside phosphorylase activity in tumour and matched gastrointestinal mucosa. Gut 1982; 23: 1072-6.

10 Finan PJ, Koklitis PA, Chisholm EM, Giles GR. Comparative levels of tissue enzymes concerned in the early metabolism of 5-Fluorouracil in normal and malignant human colorectal tissue. Br J Cancer 1984; 50: 711-5.

11 Ahmed NK, Haggit R, Welch AD. Preliminary studies of the uridine kinase activity of human colorectal adenocarcinomas. Cancer 1981; 48: 1200-6.

12 Ardalan B, MacDonald J, Cooney D, Lippman M, Schein $\mathrm{P}$. The potential for clinical application of in vitro assays predicting 5-FU sensitivity in man. Cancer Treat Rep 1981; 65: suppl. 3: 57-61.

13 Ardalan B, Conney DA, Jayaram HN et al. Mechanisms of sensitivity and resistance of murine tumours to 5-Fluorouracil. Cancer Res 1980; 40: 1431-7.

14 Hillcoat BL, McCulloch PB, Figueredo AT, Ehsan MH, Rosenfeld JM. Clinical response and plasma levels of 5-fluorouracil in patients with colonic cancer treated by drug infusion. Br J Cancer 1978; 38: 719-24.

15 Christophidis N, Vajda FJE, Lucas I, Drummer O, Moon WT, Louis WJ. Fluorouracil therapy in patients with carcinoma of the large bowel: a pharmacokinetic comparison of various rates and routes of administration. Clin Pharmacokinet 1978; 3: 330-6.

16 Seifot P, Baker L, Reed ML, Vaitkevicius VK. Comparison of continuously infused 5-fluorouracil with bolus injection in treatment of patients with colorectal adenocarcinoma. Cancer 1975; 36: 123-31. 